\title{
Asthma management in primary care: caring, sharing and working together
}

\author{
Sinthia Z. Bosnic-Anticevich \\ Affiliation: Woolcock Institute of Medical Research, University of Sydney and Sydney Local Health District, \\ Sydney, Australia.
}

Correspondence: Sinthia Z. Bosnic-Anticevich, Woolcock Institute of Medical Research, 431 Glebe Point Road, Glebe, NSW, 2037, Australia. E-mail: sinthia-bosnic-anticevich@asydney.edu.au

@ERSpublications

Why aren't primary care physicians and pharmacists collaborating more to manage and monitor asthma medication issues? http://ow.ly/YB2p6

While historically chronic illnesses have been "stewarded" by different practitioners in different countries [1] with the increasing number of people with chronic illnesses and the ever rising costs of healthcare, the primary care setting is viewed as the long-term custodian of chronic illness management [2-4]. For people with asthma, quality management in primary care is a real, viable and accessible solution to asthma care. This is reflected in guidelines $[2,5,6]$, in research trends (as we see pragmatic research sourcing participants in primary care) $[7,8]$ and it is evidenced in a multitude of primary healthcare initiatives established to support primary care physicians to optimally manage asthma in the community.

Optimal asthma management: are we achieving it? Or is it an enigma? These are questions that primary care researchers and healthcare practitioners have been burdened with for a long time. Why? Because evidence, from large-scale and population-based studies confirms that, despite our ever-increasing knowledge and the abundance of research in the practice/clinical field, asthma remains a major health and economic burden. It is estimated that $\sim 300$ million people live with asthma world-wide [2] and a high proportion of people living with asthma are classified as having poorly controlled disease [4, 9-13]. Asthma has significant economic impact both on individuals and on the healthcare system. A recent report determined that the net annual value of the burden of disease of asthma in Australia (based on disability-adjusted life years) was AUD 24.7 billion, with projected government costs for 2016-2019 being AUD 4.0 billion [14].

For primary care practitioners, the current status of asthma in the community is at the very least disappointing, if not frightening; especially given the efforts put into improving asthma care at all levels (health system, research, global reports, practice initiatives, patient support and public awareness). The reality is that the multifaceted initiatives are falling short of addressing the multifactorial issues associated with sub-optimal management in real life $[2,10,11,15-18]$ : issues spanning across patient, healthcare practitioners and healthcare-system domains $[12,19]$.

One of the major issues in practice is asthma medication use. Medication management is a well-recognised, documented and investigated aspect of asthma management. Consistently research and practice indicate that many of the issues associated with sub-optimal management of asthma are related to the way in which people use their medicines, i.e. a high proportion of patients are nonadherent and a majority do not master or maintain correct inhaler technique $[9,10]$. Effective solutions to inappropriate and incorrect asthma medication use have been identified through high quality research; however, if these strategies are being implemented in practice [2], they fail to be effective. Current data report poor adherence remaining as high as $50-90 \%$ and incorrect inhaler technique at $70-80 \%[9,10,12,20]$. There is an abundance of literature providing insights into why patients use their medications inappropriately [21, 22]; however, the solutions are complex, require significant and often additional resources, and need to be implemented continually

Received: Feb 012016 | Accepted: Feb 142016

Conflict of interest: Disclosures can be found alongside the online version of this article at erj.ersjournals.com

Copyright OERS 2016 
over time [22-24]. Is it therefore reasonable that one primary healthcare provider should take on the burden of addressing all of these issues, alone? No. It is time to call for the assistance of a medication expert: the pharmacist.

Pharmacy is one of the oldest "healing" professions and has a long history of working with physicians. In fact, wherever civilisation arises we find evidence of the roots of pharmacy, with its existence fulfilling one of man's basic needs: "the need to grasp from nature whatever might shield us from affliction" [25]. Clay tablets dating back to $2600 \mathrm{BC}$ and ancient Babylonian times provide evidence that healing involved the describing of illness, the formulation and preparation of remedies, and incantations, which were used to impart or enhance the healing quality of the medication $[25,26]$. These ancient artefacts provide evidence that during times long passed the art of diagnosing, prescribing and compounding of remedies were closely linked. They remind us that for most of recorded history, the history of pharmacy and medicine were inseparable [26]. So what has happened since then?

Times have changed and it is reasonable to say that despite recognition that teamwork is critical to chronic illness management [27, 28], primary care physicians and pharmacists generally work in insolation. This is not to say that they can't work together effectively [29, 30], but in practice they generally don't. Despite the fact that a relationship between primary care physicians and pharmacists often does exist, and attitudes towards one another are positive [31-33], interactions are generally limited to issues associated with medication dispensing [34]. While professional relationships are a complex area of practice, primary healthcare practitioners, in particular, appear to have limited understanding/confidence in the breadth of knowledge of their pharmacy colleagues, having differing needs and mismatched expectations of what their relationship should be [31]. Consequently, when it comes to asthma medication management, the assistance of the pharmacist is overlooked... despite the evidence.

Of particular relevance to this discussion is the systematic review by GARCIA-CARDENAS et al. [35] in this issue of the European Respiratory Journal. GARCIA-CARDENAS et al. [35] review the impact of pharmacist interventions on clinical asthma outcomes. Utilising the methodology and reporting standards recommended by PRISMA [36] and AMSTART [37], they review the published literature on pharmacist interventions in asthma management, drawing their conclusions from the available randomised controlled clinical trials. In so doing a range of research designs, interventions and outcomes measures were reviewed, with the conclusion that regardless of the study design pharmacists had a positive impact on asthma control. While GaRCIA-CARDENAS et al. [35] did not focus on individual interventions, but noted the need to implement consistent research methodology in pharmacy practice research, an abundance of literature exists on the impact of pharmacist interventions on asthma outcomes. In addition to improving asthma control, pharmacist interventions have been shown to effectively identify patients at risk of poorly controlled asthma, improve adherence, correct inhaler technique mastery and maintenance, and assist in the development of medication self-management practices [20, 38-48]. In summary, willing pharmacists can provide valuable support to primary healthcare physicians in their management of asthma.

And are there barriers to engaging the pharmacist in clinical care? Of course there are, but for over a decade the pharmacy profession has been transforming towards care delivery [49-59] and some of the barriers to pharmacists being acknowledged as providers of quality care are associated with the perceptions of others outside pharmacy, rather than reality. There is no doubt that pharmacists can assist in the management of asthma and they are willing to do so.

I conclude by asking the following questions. Why aren't primary healthcare physicians working with pharmacists more closely to identify, manage and monitor the medication issues? Why are pharmacists not included as a fundamental piece of the medication puzzle? And if "real-life research" is so critical to our understanding of the day-to-day issues for people living with asthma, why are pharmacists not part of research and practice initiatives? If real-life problems and solutions are what we are after, then we cannot look past pharmacy, as it doesn't get any more real-life than that!

\section{References}

1 Roberts N, Papageorgiou P, Partridge MR. Delivery of asthma and allergy care in Europe. J Asthma 2009; 46: 767-772.

2 Global Initiative for Asthma. Global Strategy for asthma management and prevention. www.ginasthma.org/ documents/4 Date last accessed: January 15, 2016. Date last updated: April, 2015.

3 Laforest L, Van Ganse E, Devouassoux G, et al. Management of asthma in patients supervised by primary care physicians or by specialists. Eur Respir J 2006; 27: 42-50.

4 Chapman KR, Boulet LP, Rea RM, et al. Suboptimal asthma control: prevalence, detection and consequences in general practice. Eur Respir J 2008; 31: 320-325.

5 National Asthma Council Australia. Australian Asthma Handbook. www.nationalasthma.org.au/handbook Date last accessed: January 15, 2016. Date last updated: April, 2015. 
6 Levy ML, Fletcher M, Price DB, et al. International Primary Care Respiratory Group (IPCRG) Guidelines: diagnosis of respiratory diseases in primary care. Prim Care Respir J 2006; 15: 20-34.

7 Roche N, Reddel HK, Agusti A, et al. Integrating real-life studies in the global therapeutic research framework Lancet Respir Med 2013; 1: e29-e30.

8 Price D, Bateman ED, Chisholm A, et al. Complementing the randomized controlled trial evidence base Evolution not revolution. Ann Am Thorac Soc 2014; 11: Suppl. 2, S92-S98.

9 Reddel HK, Sawyer SM, Everett PW, et al. Asthma control in Australia: a cross-sectional web-based survey in a nationally representative population. Med J Aust 2015; 202: 492-497.

10 Price D, Fletcher M, van der Molen T. Asthma control and management in 8,000 European patients: the REcognise Asthma and LInk to Symptoms and Experience (REALISE) survey. NPJ Prim Care Respir Med 2014; 24: 14009.

11 Price D, Dale P, Elder E, et al. Types, frequency and impact of asthma triggers on patients' lives: a quantitative study in five European countries. J Asthma 2014; 51: 127-135.

12 Nathan R, Thompson P, Price D, et al. Taking aim at asthma around the world: global results of the asthma insight and management survey in the Asia-Pacific region, Latin America, Europe, Canada, and the United States. J Allergy Clin Immunol Pract 2015; 3: 734-742.

13 Demoly P, Annunziata K, Gubba E, et al. Repeated cross-sectional survey of patient-reported asthma control in Europe in the past 5 years. Eur Respir Rev 2012; 21: 66-74.

14 Asthma Australia and National Asthma Council. The Hidden Cost of Asthma. Deloitte Access Economics, 2015.

15 Papi A, Haughney J, Virchow JC, et al. Inhaler devices for asthma: a call for action in a neglected field. Eur Respir J 2011; 37: 982-985.

16 Inhaler Error Steering Committee, Price D, Bosnic-Anticevich S, et al. Inhaler competence in asthma: common errors, barriers to use and recommended solutions. Respir Med 2013; 107: 37-46.

17 Pinnock H, Epiphaniou E, Pearce G, et al. Implementing supported self-management for asthma: a systematic review and suggested hierarchy of evidence of implementation studies. BMC Med 2015; 13: 127.

18 Pinnock H, Thomas M. Does self-management prevent severe exacerbations? Curr Opin Pulm Med 2015; 21: 95-102.

19 Levy ML, Winter R. Asthma deaths: what now? Thorax 2015; 70: 209-210.

20 Armour CL, Lemay K, Saini B, et al. Using the community pharmacy to identify patients at risk of poor asthma control and factors which contribute to this poor control. J Asthma 2011; 48: 914-922.

21 Dima AL, Hernandez G, Cunillera O, et al. Asthma inhaler adherence determinants in adults: systematic review of observational data. Eur Respir J 2015; 45: 994-1018.

22 Ovchinikova L, Smith L, Bosnic-Anticevich S. Inhaler technique maintenance: gaining an understanding from the patient's persepctive. J Asthma 2011; 48: 616-624.

23 Shams MR, Fineman SM. Asthma adherence: how can we help our patients do it better? Ann Allergy Asthma Immunol 2014; 112: 9-12.

24 Bosnic-Anticevich SZ, Sinha H, So S, et al. Metered-dose inhaler technique: the effect of two educational interventions delivered in community pharmacy over time. J Asthma 2010; 47: 251-256.

25 Miller G. A scandalously short introduction to the history of pharmacy. Canberra, Pharmaceutical Society of Australia, 2009.

26 Anderson S. Making Medicinces: A Brief History of Pharmacy and Pharmaceuticals. London, Pharmaceutical Press, 2005.

27 Wagner EH. Effective teamwork and quality of care. Med Care 2004; 42: 1037-1039.

28 Wagner EH. The role of patient care teams in chronic disease management. BMJ 2000; 320: 569-572.

29 Mehta BH, Snyder ME, Nikitas A. Developing collaborative relationships between pharmacists and other health professionals. J Am Pharm Assoc 2011; 51: 332-338.

30 Snyder ME, Zillich AJ, Primack BA, et al. Exploring successful community pharmacist-physician collaborative working relationships using mixed methods. Res Social Adm Pharm 2010; 6: 307-323.

31 Dey RM, de Vries MJ, Bosnic-Anticevich S. Collaboration in chronic care: unpacking the relationship of pharmacists and general medical practitioners in primary care. Int J Pharm Pract 2011; 19: 21-29.

32 Kucukarslan S, Lai S, Dong Y, et al. Physician beliefs and attitudes toward collaboration with community pharmacists. Res Social Adm Pharm 2011; 7: 224-232.

33 Van C, Costa D, Abbott $\mathrm{P}$, et al. Community pharmacist attitudes towards collaboration with general practitioners: development and validation of a measure and a model. BMC Health Serv Res 2012; 12: 320.

34 Van C, Mitchell B, Krass I. General practitioner-pharmacist interactions in professional pharmacy services. J Interprof Care 2011; 25: 366-372.

35 Garcia-Cardenas V, Armour C, Benrimoj SI, et al. Pharmacists' interventions on clinical asthma outcomes: a systematic review. Eur Respir J 2016; 47: 1134-1143.

36 Liberati A, Altman DG, Tetzlaff $\mathrm{J}$, et al. The PRISMA statement for reporting systematic reviews and meta-analyses of studies that evaluate health care interventions: explanation and elaboration. $J$ Clin Epidemiol 2009; 62: e1-e34.

37 Shea BJ, Grimshaw JM, Wells GA, et al. Development of AMSTAR: a measurement tool to assess the methodological quality of systematic reviews. BMC Med Res Methodol 2007; 7: 10.

38 Mehuys E, Van Bortel L, De Bolle L, et al. Effectiveness of pharmacist intervention for asthma control improvement. Eur Respir J 2008; 31: 790-799.

39 Basheti IA, Armour CL, Bosnic-Anticevich SZ, et al. Evaluation of a novel educational strategy, including inhaler-based reminder labels, to improve asthma inhaler technique. Patient Educ Couns 2008; 72: 26-33.

40 Basheti IA, Reddel HK, Armour CL, et al. Counseling about turbuhaler technique: needs assessment and effective strategies for community pharmacists. Respir Care 2005; 50: 617-623.

41 Basheti IA, Reddel HK, Armour CL, et al. Improved asthma outcomes with a simple inhaler technique intervention by community pharmacists. J Allergy Clin Immunol 2007; 119: 1537-1538.

42 Armour C, Bosnic-Anticevich S, Brillant M, et al. Pharmacy Asthma Care Program (PACP) improves outcomes for patients in the community. Thorax 2007; 62: 496-502.

43 Bosnic-Anticevich SZ, So S, Armour CL, et al. MDI technique: effect of education interventions delivered in community pharmacy over time. Am J Respir Crit Care Med 2003; 167: Suppl., A896. 
Kritikos V, Saini B, Bosnic-Anticevich SZ, et al. Innovative asthma health promotion by rural community pharmacists: a feasibility study. Health Promot J Austr 2005; 16: 69-73.

Naik-Panvelkar P, Saini B, LeMay KS, et al. A pharmacy asthma service achieves a change in patient responses from increased awareness to taking responsibility for their asthma. Int J Pharm Pract 2015; 23: 182-191.

Saini B, Filipovska J, Bosnic-Anticevich S, et al. An evaluation of a community pharmacy-based rural asthma management service. Aust J Rural Health 2008; 16: 100-108.

Smith L, Bosnic-Anticevich SZ, Mitchell B, et al. Treating asthma with a self-management model of illness behaviour in an Australian community pharmacy setting. Soc Sci Med 2007; 64: 1501-1511.

Giraud V, Allaert F, Roche N. Inhaler technique and asthma: feasibility and acceptability of training by pharmacists. Respir Med 2011; 105: 1815-1822.

Benrimoj S, Frommer M. Community pharmacy in Australia. Aust Health Rev 2004; 28: 238-246.

Benrimoj SI, Langford JH, Berry G, et al. Economic impact of increased clinical intervention rates in community pharmacy. A randomised trial of the effect of education and a professional allowance. Pharmacoeconomics 2000; 18: 459-468.

Roberts A, Benrimoj SI, Chen TF, et al. Implementing cognitive services in community pharmacy: a review of facilitators used in practice change. Int J Pharm Pract 2006; 3: 163-170.

Feletto E, Wilson LK, Roberts AS, et al. Measuring organizational flexibility in community pharmacy: building the capacity to implement cognitive pharmaceutical services. Res Social Adm Pharm 2011; 7: 27-38.

Feletto E, Wilson LK, Roberts AS, et al. Building capacity to implement cognitive pharmaceutical services: Quantifying the needs of community pharmacies. Res Social Adm Pharm 2010; 6: 163-173.

Feletto E, Wilson LK, Roberts AS, et al. Flexibility in community pharmacy: a qualitative study of business models and cognitive services. Pharm World Sci 2010; 32: 130-138.

5 Moullin JC, Sabater-Hernandez D, Fernandez-Llimos F, et al. Defining professional pharmacy services in community pharmacy. Res Social Adm Pharm 2013; 9: 989-995.

Roberts AS, Benrimoj SI, Chen TF, et al. Practice change in community pharmacy: quantification of facilitators. Ann Pharmacother 2008; 42: 861-868.

Roberts AS, Benrimoj SI, Chen TF, et al. Understanding practice change in community pharmacy: a qualitative study in Australia. Res Social Adm Pharm 2005; 1: 546-564.

Roberts AS, Hopp T, Sorensen EW, et al. Understanding practice change in community pharmacy: a qualitative research instrument based on organisational theory. Pharm World Sci 2003; 25: 227-234.

Whitehead PA, Sunderland VB, Benrimoj SI. The 'general practice' pharmacist. Aust J Pharm 2003; 84: 24-27. 